\title{
Identification of a novel 4.6-kb genomic deletion in presenilin-1 gene which results in exclusion of exon 9 in a Finnish early onset Alzheimer's disease family: an Alu core sequence-stimulated recombination?
}

\author{
Mikko Hiltunen ${ }^{1,2}$, Seppo Helisalmi ${ }^{1,2}$, Arto Mannermaa ${ }^{2}$, Irina Alafuzoff ${ }^{1,3}$, \\ Anne Maria Koivisto ${ }^{1}$, Maarit Lehtovirta ${ }^{1}$, Mia Pirskanen ${ }^{1,2}$, Raimo Sulkava ${ }^{4}$, \\ Auli Verkkoniemi ${ }^{5}$ and Hilkka Soininen ${ }^{1}$
}

\begin{abstract}
${ }^{1}$ Department of Neurology, University Hospital and University of Kuopio; ${ }^{2}$ Chromosome and DNA Laboratory of the Division of Diagnostic Services; ${ }^{3}$ D epartment of Pathology, University Hospital of Kuopio; ${ }^{4}$ Department of Public Health and General Practice, Division of Geriatrics, University and University Hospital of Kuopio; ${ }^{5}$ Department of Clinical Neuroscience, Helsinki University Central Hospital, Finland
\end{abstract}

Mutations in the presenilin-1 (PS-1) gene have been shown to cause early onset Alzheimer's disease (EOAD) in an autosomal dominant manner. We have identified a novel 4.6-kb genomic deletion in the PS-1 gene in a Finnish EOAD family, which leads to an inframe exclusion of exon $9(\Delta 9)$ from the mRNA transcript. This germline mutation results in a similar alteration in mRNA level as previously described with the variant $A D$ and the $\triangle 9$ splice-site mutations. In this present EOAD family, the clinical and neuropathological phenotype of patients are those of the typical AD without indications of spastic paraparesis or 'cotton wool' plaques, which are the hallmarks of the variant AD. A sequence analysis of the deletion crossover site of the mutant and corresponding wild type regions revealed complete homology with the recombigenic 26 bp Alu core sequence at intron 8. In addition, a segment at the intron 9 breakpoint displayed homology with the core sequence, but comparison of the 5' and 3' breakpoint sequences did not reveal significant identity favouring involvement of Alu core sequence-stimulated non-homologous recombination rather than Alu-mediated homologous pairing of the fragments. This study shows that large genomic rearrangements can affect the EOAD gene PS-1 through a mechanism, which may involve Alu core sequence-stimulated recombination. European Journal of Human Genetics (2000) 8, 259-266.

Keywords: Alzheimer's disease; presenilin-1; genomic deletion; Alu core sequence; non-homologous recombination; substitution E318G

\section{Introduction}

Alzheimer's disease (AD) is the most common cause of progressive neurological disorder leading to dementia. It is neuropathologically characterised by senile plaques and

Correspondence: Mikko Hiltunen, MSc, Chromosome and DNA Laboratory, Kuopio University Hospital, P.O. Box 1777, FIN-70211 Kuopio, Finland. Tel: +35817 172729; Fax: +35817 172726; E-mail: mhiltune@messi.uku.fi

Received 31 August 1999; revised 7 October 1999; accepted

8 November 1999 neurofibrillary tangles in the cortex of the brain. The molecular mechanisms leading to $A D$ are not well understood, but it has a genetic etiology, which is most evident in the case of early onset AD (EOAD). To date, highly penetrant mutations in three genes are known to cause autosomal dominant EOAD (onset age before 65 years): amyloid precursor protein (APP) gene on chromosome21, presenilin-1 (PS-1) gene on chromosome 14 and presenilin-2 (PS-2) gene on chromosome1. ${ }^{1-4}$ Together, these genes account for approximately $1 \%$ of the total $A D$ population while the 
mutations within the PS-1 gene are more frequently by the cause of EOAD than the mutations in other known genes.

Over 50 different PS- 1 gene mutations have been reported in approximately 80 families of various ethnic origins. Nearly all the molecular genetic changes are missense mutations leading to increased production of amyloidogenic $A \beta 42$ peptide by gain-of-function or dominant-negative mechanism affecting the APP processing. The exceptions are the splice-site mutations resulting in an inframe skipping of exon $9(\Delta 9)$ accompanied by a point mutation at the splice junction codon 290 (S290C), and the deletion of exon 9 from the mRNA by an yet undetermined mechanism. ${ }^{5-8}$ In addition, mutation in the intron 4 splice site junction of the PS-1 gene results in two shortened transcripts with premature termination codons and one full-length transcript with insertion of three nucleotides. ${ }^{9,10}$ However, in vivo experiments showed only the presence of the full-length PS-1 protein with one extra amino acid (Thr) in brain extracts and lymphoblast lysates of mutation carriers. PS-1 $\Delta 9$ mutations lead to the exclusion of 28 amino acids from the cytoplasmic loop domain of the protein, which contains the endoproteolytic cleavage site. In the normal physiological situation, PS-1 holoprotein undergoes well-controlled proteolytic processing, which produces about $17 \mathrm{kDa}$ carboxyl-terminal and about $28 \mathrm{kDa}$ amino-terminal fragments. Lack of the cleavage site in $\Delta 9$ deletions results in the accumulation of uncleaved PS-1 protein. Recently, it was shown that the point mutation (S290C) at the exon 8/10 splice junction rather than the lack of proteolytic processing of PS- 1 in the $\Delta 9$ mutation, is the cause of the enhancement of pathological functions. ${ }^{11}$

In this study, we have identified a novel $4.6-\mathrm{kb}$ genomic deletion in the PS-1 gene leading to exclusion of exon 9 in a Finnish EOAD family. $A D$ patients carrying this genomic deletion showed the typical phenotypic features of $A D$ without indications of spastic paraparesis or 'cotton wool' plaques described in the variant $A D$ patients. ${ }^{8}$ We suggest here that the Alu core sequence-stimulated non-homologous event may underlie the genomic rearrangement in this particular EOAD family.

\section{Family and methods Family}

The family had several members with early onset dementia and the transmission of the disease indicated autosomal dominant inheritance (Figure1). We were able to perform neurological examinations, neuropsychological tests, CT scanning and differential diagnostic laboratory tests for three affected individuals (II:2, II:4 and II:5). For patient II:2, EEG, SPECT, and psychiatric evaluation were made and the patient was diagnosed as having probable AD. Brain biopsy was taken

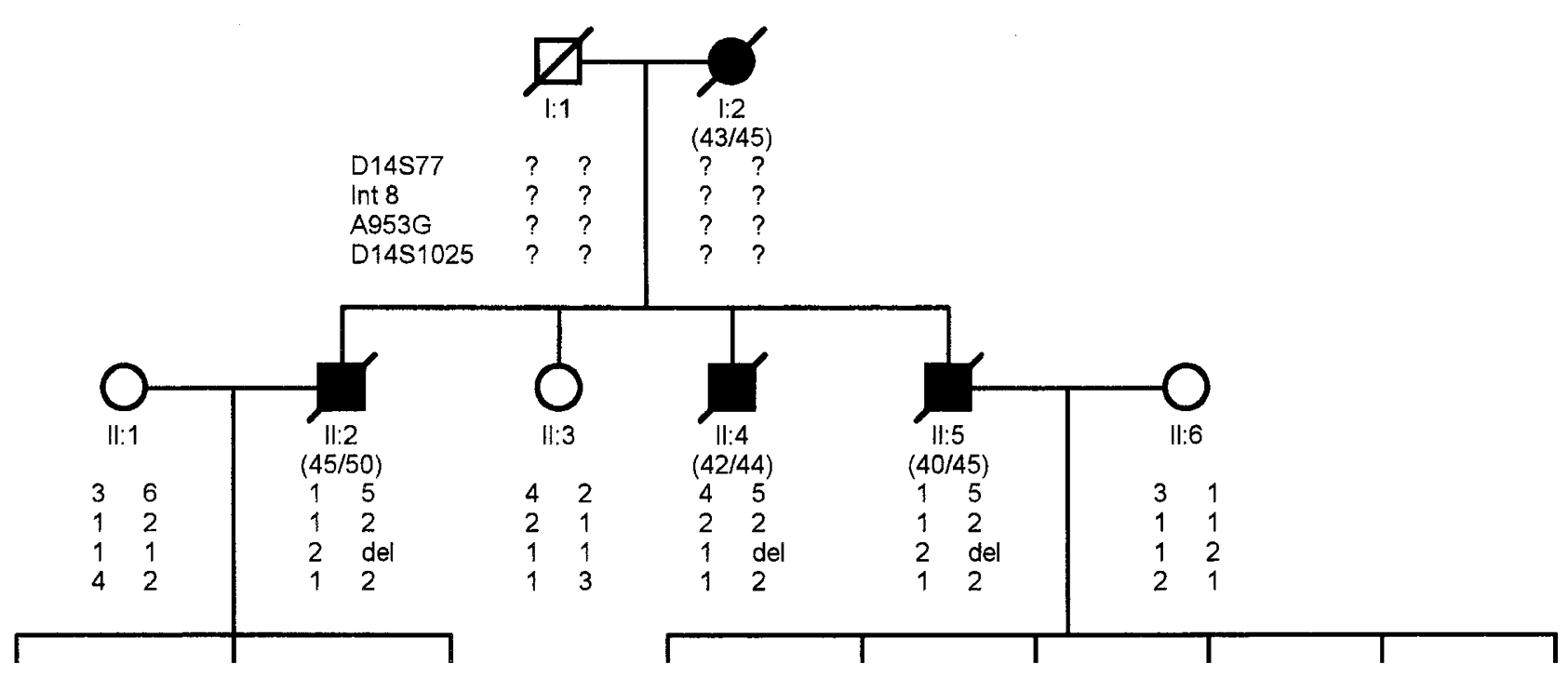

Figure 1 Haplotype analysis with markers flanking or within the PS-1 gene on chromosome 14. Affected individuals are denoted by a filled symbol and the ages at onset and at death, respectively, are indicated in parentheses. Haplotype 5-2-del-2 is shared by affected family members (II:2 = probable $A D ; \|: 4=$ definite $A D ; \|: 5=$ probable $A D)$. Int 8 = intron 8 polymorphism; $A 953 G=A(1)$ to $G(2)$, a substitution leading to the amino acid change from glutamic acid to glycine at the codon 318 (E318G). 
from patient II:4 and the definite AD was diagnosed (see neuropathology). Patients $11: 2,11: 4$ and $11: 5$ were regularly examined by neurologists after the disease onset. Patient $1: 2$, who had died long before our present study, was clinically examined in the 1970s and was diagnosed as demented. In addition, 51 control subjects and 102 familial and sporadic early and late onset AD patients from Eastern Finland, who fulfilled the NINCDS-ADRDA criteria for definite, probable, or possible $A D^{12}$ were used for mutation screening.

\section{DNA extraction}

Genomic DNA was extracted from white blood cells by a standard procedure ${ }^{13}$ and from paraffin-embedded tissues in postmortem $A D$ cases as described by Isola et al $^{14}$

\section{Sequence analysis}

The exons of open reading-frame of the PS-1 gene (exons312) were PCR amplified with similar primers and conditions as reported by Hutton et al. ${ }^{15}$ PCR products were purified and cycle-sequenced with the ABI PRISM 310 genetic analyser (Perkin Elmer, Foster City, CA, USA) by utilising the dReady Dye Terminator Cycle Sequencing kit with AmpliTaq DNA polymerase, FS (Perkin Elmer, Foster City, CA, USA).

\section{Haplotyping}

Microsatellite markers D14S77 and D14S1025 were genotyped using fluorescent-labelled PCR-primers obtained from the Genome Database (http://gdbWWW.gdb.org/). PCR amplifications were performed using the standard procedure. ${ }^{16}$ The sizes of PCR products were determined with $A B I$ PRISM 310 genetic analyser (Perkin Elmer). Intron 8 polymorphism and E318G substitution in exon 9 were analysed by PCR using mismatch primers and restriction enzyme analysis as previously described by Wragg et $\mathrm{al}^{17}$ and Dermaut et $\mathrm{al},{ }^{18}$ respectively.

\section{RT-PCR analysis}

Total RNA was extracted from peripheral lymphocytes using Trizol Reagent (Gibco BRL, Grand Island, NY, USA). Poly ( $\mathrm{A}^{+}$) mRNA was captured using mRNA Capture Kit (Boehringer Mannheim GmbH, Germany) followed by RT-PCR (Titan ${ }^{\text {TM }}$ One Tube RT-PCR System, Boehringer Mannheim) with exons8 (DEL9F:5'-GCT GTT TTG TGT CCG AAA GGT CCA CTT CGT ATG CTG-3') and 10 (DEL9R: 5'-CTC TGG GTC TTC ACC AGC GAG GAT ACT GCT GGA AAG-3') specific primers (Figure3B). Truncated 261 bp PCR product was excised from $1 \%$ low melting agarose gel and cycle-sequenced in both directions (see sequence analysis of PS-1 exons).

\section{Genomic DNA analysis}

To define the del etion breakpoint region, PCR reactions were carried out using different primer pairs located at the introns 8 and 9 with Expanded Long PCR System (Boehringer Mannheim). A reaction with primers IN8F4 (5'-AAG TGG TTC ACT CTG GGA GCT TAA C-3') and IN9F5 (5'-GAA AGC
TCT TCC TCC ATC CTT CAG C-3') (Figure3B) revealed a novel 1.6-kb PCR-product, which was seen only in the affected member of the family. The PCR-product was cyclesequenced in both directions. For diagnostic purposes, multiplex PCR primers DE8F1 (5'-GTG GAC ATT GAT TTT CAT GTT AC-3'), DE8R2 (5'-TCT AAT ACT CAG GCT TCT TGA AG-3') and DE9R1 (5'-TAT ACC TAC ATG CTC ACA GAC AAT C-3') (Figure $3 B$ ) were designed on the basis of sequence data to amplify control (504 bp) and deleted (290 bp) fragments. The cycle parameters were $3 \mathrm{~min}$ initial denaturation at $94^{\circ} \mathrm{C}$ followed by 30 cycles at $94^{\circ} \mathrm{C}$ for $1 \mathrm{~min}, 52^{\circ} \mathrm{C}$ for $45 \mathrm{~s}$, and $72^{\circ} \mathrm{C}$ for $1 \mathrm{~min}$. Alu and other repeat sequences were identified using the BLAST2.0 program (http:// www.ncbi.nlm.nih.gov/) and the Repeat Masker Server (http://ftp/genome/washington/edu/).

\section{Neuropathology}

Cortical biopsy taken in 1992 from the patient II:4 was in two pieces, each approximately $10 \mathrm{~mm}$ in diameter. After fixation and paraffin embedding seven- $\mu \mathrm{m}$ thick sections were cut and stained with hematoxylin-eosin, thioflavin-S and modified Bielschowsky silver impregnation. Furthermore, with immunohistochemical stainings, $\beta$-amyloid aggregates ( $\beta$ A4 - DAKO (Glostrup, Denmark) M872, dilution 1:100; $\beta A 40$ and $\beta A 42$ - USPeptides (New York, NY, USA) 1:1500; 4G8 and 6 E10 - Senetek (St. Louis, MO, USA) 1:2000), neurofibrillary tangles (AT8 - Innogenetics (Ghent, Belgium) BR03, 1:500), Lewy inclusions and threads (Synuclein 1, Transduction Lab (Los Angeles, CA, USA) S63320, 1:1000; $\alpha$-synuclein, ZYMED (San Francisco, CA, USA) LB509, 1:500), reactive astrocytes (GFAP - DAKO Z0334) and activated microglia (HLA DR DAKO M 775) and complement components (C1q - DAKO A0136, C3C - DAKO A0062, C3d - DAKO A0063 and C5 DAKO A0055, 1:100) were visualised.

\section{Results}

A substitution E318G in exon 9, which was recently shown not to relate causally to $A D,{ }^{18}$ was detected in two affected cases and in eight healthy individuals by sequencing the coding region of PS-1 (Figure1). No other PS-1 gene alterations were detected. Five out of ten substitution carriers were homozygous for the E318G variant. Segregation of the E318G substitution from the family members to their offspring did not follow normal Mendelian inheritance patterns, since genetic inconsistency was observed in some individuals. To determine the cause of this inconsistency, two microsatellite markers around the PS-1 gene and one biallelic marker located at the 5 ' end of intron 8 were analysed to construct extended haplotypes. All markers showed a normal segregation pattern. Therefore, the most likely explanation for the non-Mendelian segregation pattern of the E318G substitution was a heterozygous deletion around exon 9, which was defined to start downstream from the biallelic marker of intron 8. Upon further scrutiny, all the AD cases carried the same haplotype 5-2-del-2 for D14S77, intronic polymor- 
phism, E318G, and D14S1025, respectively.

RT-PCR analysis using a lymphocyte sample carrying the presumed disease-associated haplotype 5-2-del-2 was performed (Figure2A). A truncated $261 \mathrm{bp}$ fragment was revealed with PCR-primers located within the exons 8 and 10 (Figure 3B), and the sequence analysis of the abnormal RT-PCR fragment showed an inframe deletion of codons290319 corresponding to exon 9 (data not shown). In accordance with this result, RT-PCR performed with exon 7 and 12 specific primers produced a truncated fragment lacking the alternatively spliced exon $8^{19}$ and also exon 9 (data not shown). Therefore, abnormal exclusion of the exon 9 from PS-1 CDNA suggested that the breakpoint regions of genomic deletion were located in the introns 8 and 9.

In order to define the deletion breakpoints at the genomic level, long PCR amplifications with intron 8 and 9 specific primers were conducted. A PCR reaction with primers IN8F4 and IN 9F5 located approximately 2.7 and 3.3-kb from exon 9, respectively (Figure $3 \mathrm{~B}$ ), produced a novel $1.6-\mathrm{kb}$ fragment, which was only seen in the affected family member (data not shown). Diagnostic PCR primers were designed on the basis of sequence data obtained from $1.6-\mathrm{kb}$ product (Figure 3B) and the screening of the affected family members showed a heterozygote $290 \mathrm{bp}$ fragment in subjects carrying the haplotype 5-2-del-2 (Figure2B). Sequence analysis of the $290 \mathrm{bp}$ fragment revealed flanking sequences of the deletion. This allowed us to determine that the total deletion was $4555 \mathrm{bp}$ large and consists of 1.6-kb distal part of intron 8, exon 9 and a 2.9-kb proximal part of intron 9 (Figures $3 A$ and $B$ ). Deletion analysis of $102 \mathrm{AD}$ patients and 51 control subjects from Eastern Finland did not reveal any additional cases with the novel PS-1 $\Delta 9$ mutation.

In the neuropathological examination, the HematoxylinEosin staining of the frontal cortex sections visualised both grey and white matter. In the grey matter characteristic lesions for AD, such as amyloid plaques (AP) with a central core formation and neurofibrillary tangles among the neuronal population were observed (Figure4A). Round plaques without cellular participation as described in the entity of variant $A D$ with cotton wool plaques were not seen. Thioflavin-S staining demonstrated several amyloid cores and cerebral amyloid angiopathy (CAA), both in the parenchyme and in the leptomeninges. Bielshowsky silver impregnation demonstrated numerous neurofibrillary tangles, neuritic plaques and senile/amyloid plaques (Figure4B). Alzheimer's degenerative changes were sufficient for the diagnosis of definite $A D$ according to CERAD. ${ }^{20}$ Beta-amyloid aggregates were visualized with immunohistochemical staining (Figure $4 C$ ) in the vessel walls of the neuropil and leptomeninges (CAA) and in the neurophil as APs. These APs were quite numerous, round in shape and varied in size. Numerous APs and CAA were labelled with antibodies $\beta A 4, \beta A 42,6 E 10$ and
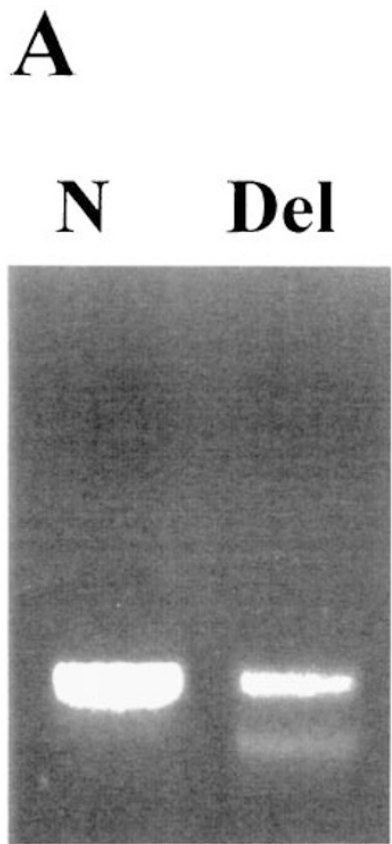

-348 bp $-261 \mathrm{bp}$
B

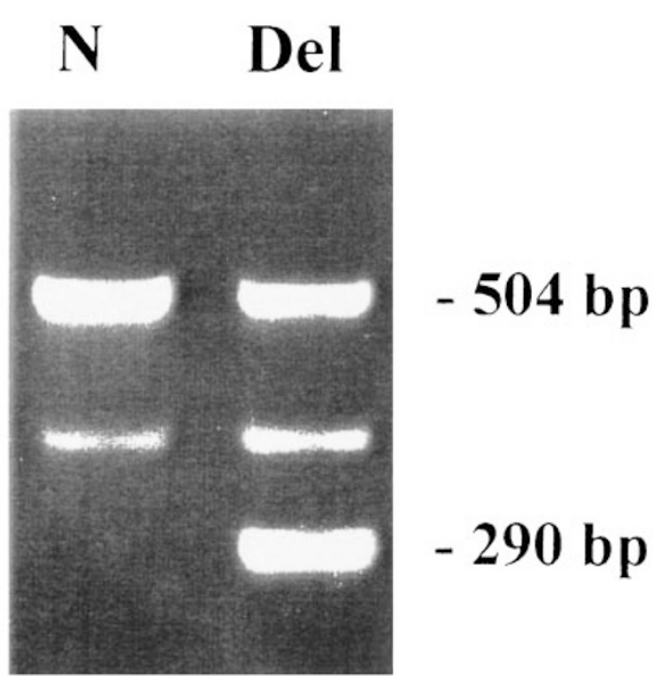

Figure 2 Molecular analysis of the PS1 deletion. $\mathrm{N}=$ normal; Del = deletion. A RT-PCR analysis of RNA extracted from lymphocytes. To avoid alternatively spliced fragments of exon 8 produced in lymphocytes, cDNAs were amplified using exon 8 and 10 specific primers. Truncated $261 \mathrm{bp}$ fragment including the exons 8 and 10 was excised from the agarose gel and sequenced. B DNA analysis of genomic deletion using the intron 8 and 9 specific PCR-primers. Multiplex PCR reactions with primers DE8F1, DE8R2 and DE9R1 were performed to amplify control (504bp) and deleted fragments (290 bp). The intermediate DNA fragment seen in both $A D$ and control cases was the product of unspecific PCR-amplification. 
4G8 whereas only few were labelled with antibodies against the short $\beta A 40$. Some amyloid aggregates were also detected in the white matter. Numerous neurofibrillary tangles (NFT), neuropil threads (NT) and neurites in neuritic plaques (NP) were visualised with phosphorylated PHF-Tau antibody (Figure4D). Furthermore, positive NTs were also seen in the white matter. Intra neuronal inclusions labelled with synuclein-1 or with $\alpha$-synuclein antibodies could not be detected, even though the latter antibody labelled some of the plaques. Prion protein staining did not reveal changes seen in prion diseases. Quite strong inflammatory response was noted both as numerous activated microglial cells (AM) and reactive

A

Intron 8 GCATAAAGAA AGAAAACCTA ATAAATCGCT GGTGGCTTCA TTTCCAAAAG

Deletion GCATAAAGAA AGAAAACCTA ATAAATCGCT GGTGGCTTCA TTTCCAAAAG

Intron 9 CAGCTCACAG AGCATGCTGC CCCAGCTGCA CCTCCCCTGC TGCAGCTGCC

Intron 8 GCTATGGAAA TCCATAAACA GGCtgggTGC AGTGGCTCAT GCCTGTAATC

Deletion GCTATGGAAA TCCATAAACA GGCtgggCCG CTGCTGCCAT CAAGACCACT

Intron 9 ATCTTTGCAG_CAGCCACTCC AGAtgggCCG CTGCTGCCAT CAAGACCACT

Intron 8 CTAGCACTTT GGGAGGCTGA GGCGGGAGGA TIGCTTGAGC CCAGGAGTTT

Deletion AGTAAACCTG ATAGAAAAGT AAGAAATATA CTGGAAAGAA TTGCCACAAG

Intron 9 AGTAAACCTG ATAGAAAAGT AAGAAATATA CTGGAAAGAA TTGCCACAAG

Intron 8 GAGTCTGGCC TGGGCAACGT AGTGAGACCC TGTTTTTAGA AAAAATGAAG

Deletion CCTGGCTCTT GIGTTAACCT GTGTTAAGCT AAAGAAAATC AAATGATTGT

Intron 9 CCTGGCTCTT GTGTTAACCT GTGTTAAGCT AAAGAAAATC AAATGATTGT

Intron 8 ATAAAAAACT AATCCATAAA CCTCATACTT GGTGGTTGCC CTTCAGTTTT

Deletion CTGTGAGCAT GTAGGTATAT ATGTATGTGA GTGAGTGATA CAACAGAATT

Intron 9 CTGTGAGCAT GTAGGTATAT ATGTATGTGA GTGAGTGATA CAACAGAATT

B

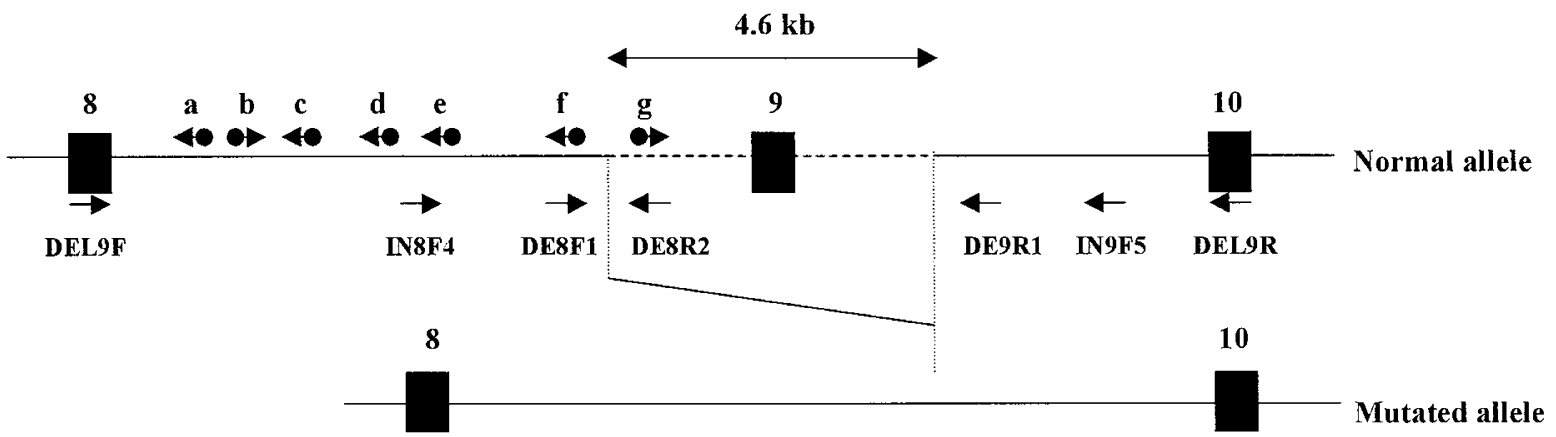

Figure 3 Sequence analysis of the region flanking the deletion crossover site. A Genomic sequences of PS-1 involved in the recombination process. Recombinogenic 26 bp Alu core sequence (double line) and a sequence displaying homology with FLAM C repeat sequence (underlined) located in the intron 8 are shown. The presumed homology segment for Alu core sequence is indicated in the intron 9 (dashed line). B Schematic presentation of the normal and mutated alleles of PS-1 gene. The location and orientation of PCR primers (arrows) and human Alu consensus sequences (modified arrows) are indicated in the introns8 and 9. Alu subfamily sequences are composed of two homologous portions arranged in a head to tail dimer of approximately $130 \mathrm{bp}$. 

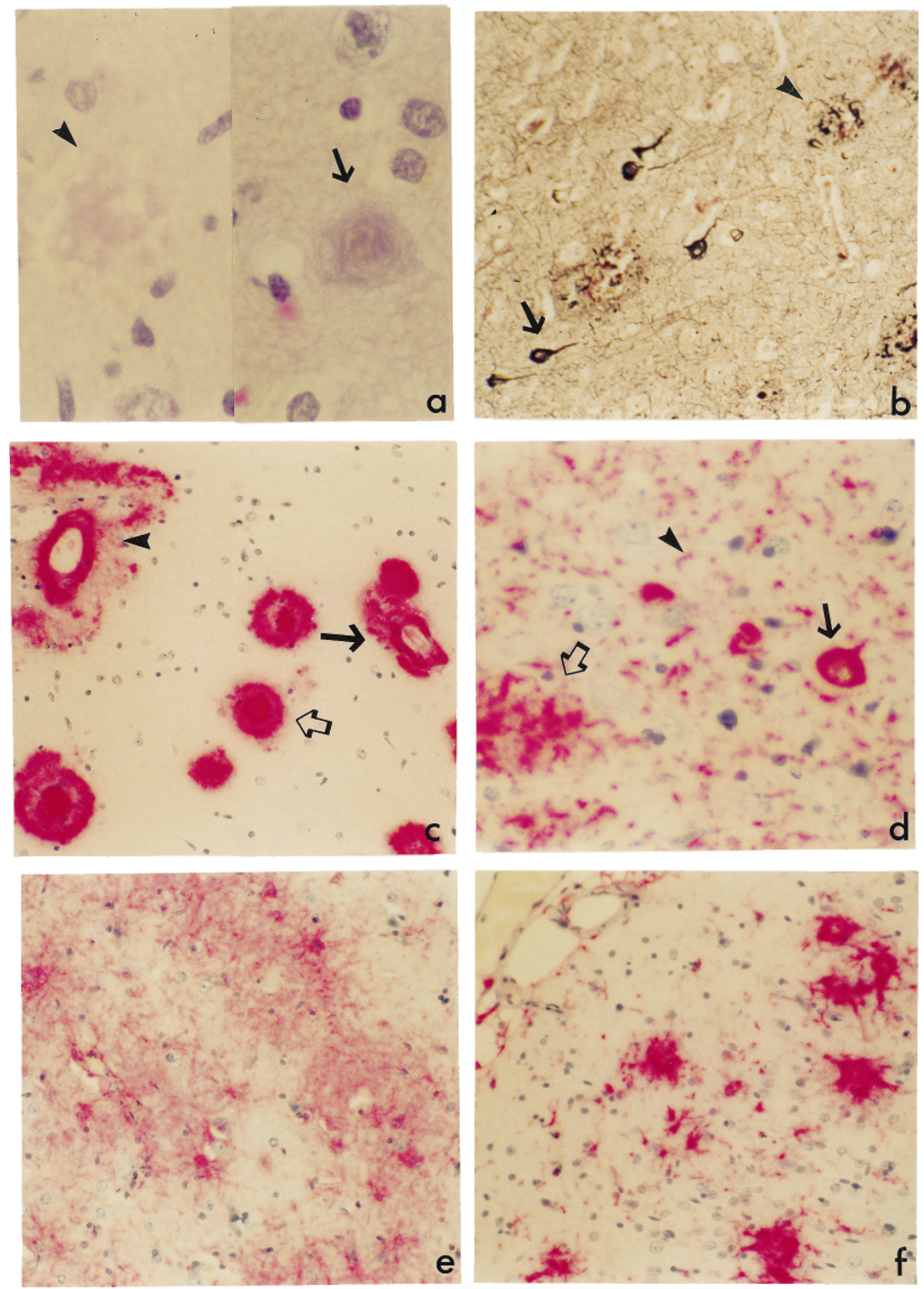

Figure 4 Neuropathological examination of the frontal cortex section. A Hematoxylin-eosin staining, magnification $200 \times$. Note amyloid plaques (AP) with central core formation. B Bielshowsky silver impregnation, magnification $100 \times$. Note numerous NFTs (arrow) and neuritic plaques (arrowhead). C Immunohistochemical labelling of $\beta A 4$ protein, magnification $100 \times$. Labelling is seen in the neuropil (open arrow) as APs and in the vessel walls as CAA, of both the neuropil (arrow) and the leptomeninges (arrowhead). D Immunohistochemical labelling of neurofibrillary degeneration (AT8), magnification $200 \times$. Numerous NFTs (arrow), neuropil threads (NT) (arrowhead) and neurites in neuritic plaques (NP) (open arrow) can be

seen. E Immunohistochemical labelling of reactive astrocytes (GFAP), magnification $100 \times$. Note numerous reactive astrocytes diffusely within the grey matter. F Immunohistochemical labelling of activated microglia (HLA DR), magnification $100 \times$. Note numerous activated microglial cells primarily located centrally in the plaques.

\section{European Journal of Human Genetics}


astrocytes (RA). AMs (Figure 4F) were primarily located centrally in the plaques, whereas the RAs (Figure4E) were seen more diffusely within the grey matter. Both cell types were also identified within the white matter. Moderate complement factor labelling was observed in association with the plaques with antibodies directed to the C3d factor, and weak staining with antibodies directed to $\mathrm{C} 3 \mathrm{c}$ and $\mathrm{Clq}$ factors, also in association with the plaques, whereas no staining was detected with antibodies directed to the C5 complement factor.

\section{Discussion}

Recently, Crook et $\mathrm{al}^{8}$ described a novel variant form of AD in a Finnish pedigree with spastic paraparesis and unusual eosinophilic plaques resembling cotton wool balls. These plaques showed uneven peripheral immunoreactivity for $A \beta$ and were not discernible from the background by Thioflavin$\mathrm{S}$. The molecular genetic basis of the variant form of $A D$ was shown to be a deletion of exon 9 from the PS-1 mRNA, whereas no genomic DNA alteration was identified. In this present article, we have identified a novel $4.6-\mathrm{kb}$ genomic deletion in the PS-1 gene in one Finnish EOAD family, which leads to the inframe exclusion of exon 9 from the mRNA transcript. Although the genomic deletion leads to a similar end result at the mRNA level as described by Crook et al, ${ }^{8}$ the phenotypic features of the AD patients clearly resemble the typical $A D$ rather than the variant $A D$.

Disease-causing genomic rearrangements including large deletions, inversions or duplications, have not been previously demonstrated to occur in the EOAD genes. In contrast, germline and somatic rearrangements of the genomic DNA are frequent in various cancer types, and a common mechanism giving rise to these alterations is Alu-mediated homologous recombination. ${ }^{21,22}$ The well-conserved region of Alu sequences is frequently found at or close to the sites of homologous and non-homologous recombination and has been proposed to be a hot spot of recombination. ${ }^{23}$ Also in this particular case, a complete $26 \mathrm{bp}$ Alu core sequence was located near the tetranucleotide sequence TGGG shared by the both recombining fragments at the intron 8 (Figure $3 A$ ). In addition, a small segment upstream from the TGGG sequence displayed homology with the core sequence also in the 3' breakpoint region, indicating involvement of the Alu core element, or part of it, in both recombining fragments. Comparison of the breakpoint regions and the nearby intron regions, however, did not reveal any major homology between $5^{\prime}$ and $3^{\prime}$ sequences favoring the Alu core sequencestimulated non-homologous recombination rather than the Alu-mediated homologous pairing of the fragments. Thus, in accordance with findings showing the involvement of at least one complete or partial Alu core element in the rearrangement processes, ${ }^{24,25}$ the present study al so addresses the importance of Alu core sequence-stimulated functions in the non-homologous recombination events.
The clinical history of AD patients with the novel PS-1 $\Delta 9$ mutation did not reveal any indication s of spastic paraparesis (paralysis of legs) or any other major motor-neuronal disturbances. This is crucial since spastic paraparesis is the main clinical feature associated with variant $A D$ patients. ${ }^{8}$ In contrast, the common clinical manifestations in AD patients described here are memory impairment and rapid progression of the disease after onset. The mean disease onset age in this EOAD family is 43.5 years, which is close to that previously reported with the $\Delta 9$ splice-site mutation family. ${ }^{5}$ Very early onset ages (from 40 to 45 years of age) with the novel $\Delta 9$ mutation, is in agreement with the findings showing that the del etion of the PS-1 exon 9 has the greatest impact on $A \beta 42$ production in various transfected cell lines ${ }^{26,27}$ and this is suggested to promote cerebral $A \beta$ deposition and induce $A D .{ }^{28}$ In accordance with the clinical features, neuropathology was typical of $A D$ in this family with numerous amyloid plaques with a central core formation, neurofibrillary tangles, neuritic plaques, and reactive astrocytes and microglial cells in association with the plaques. More importantly, neuropathological examination did not reveal 'cotton wool' plaques, which are the hallmark of the variant AD. The phenotypic data, therefore, suggests a clear difference between the variant $A D$ patients with spastic paraparesis and the EOAD patients described here, although the molecular genetic basis in both cases is the abnormal splicing of exon 9.

In addition to the large genomic deletion found in the PS-1 gene, a substitution E318G was detected in the exon 9 among the family members. The role of the E318G variant is controversial, since it has been reported to be causative for $A D,{ }^{29}$ but al so to be a rare polymorphism not associated with AD. ${ }^{18}$ Our studies using the Finnish AD and control population indicate that the E318G variant is probably nonpathogenic since a small group of age-matched control subjects also carries the alteration (S Helisalmi et al, 1999, unpublished data). However, the allele frequency of the E318G variant is significantly increased in both familial and sporadic AD groups when compared with the control group, suggesting that it may be a risk factor in AD. It is possible that the variant is in linkage disequilibrium with yet another change located perhaps in the promoter or regulatory regions of the PS-1 gene. The effect of the E318G variant on this particular family could be evaluated by a suggestion made by Mehta et al. ${ }^{27}$ The age of onset of the PS-1-caused disease could be influenced by other genetic factors contributing either in a cis- or trans-acting way. In this respect, however, the E318G variant does not seem to modulate the age of onset in this family (Figure 1 ) and its possible role in $A D$ remains to be determined in further studies.

In conclusion, we have identified a novel $4.6-\mathrm{kb}$ genomic deletion in the PS-1 gene in a Finnish EOAD family, which leads to the exclusion of exon 9 from the PS-1 mRNA. We propose that an Alu core-stimulated non-homologous recombination event underlies this rearrangement. Moreover, we 
could not detect further cases with the mutation, indicating that the frequency of this novel $\Delta 9$ alteration in the Eastern Finnish AD population is low. The expression of both the wild type and truncated PS-1 transcripts probably rules out the possibility that pathogenic effects would be exerted through haploinsufficiency. Therefore, the possible mechanism of pathogenesis in this novel $\Delta 9$ mutation may be the same as previously suggested by Citron et $\mathrm{al}^{28}$ and Ishii et al. ${ }^{30}$ Increased production and deposition of amyloidogenic A $\beta 42$ could then be the fundamental pathological determinant promoting AD. Finally, the phenotypic differences between various $\Delta 9$ mutation families suggest that there exist modifying factors, which may participate in the $A D$ process in addition to the main causative agent.

\section{Acknowledgements}

The authors thank Dr Garry Wong for helpful comments and Ms Marjo Heikkinen for skilful technical help. The study was supported by the Health Research Council of the Academy of Finland, EVO grants (5032 and 5142) of Kuopio University Hospital and the Helsingin Sanomat Centennial Foundation. $\mathrm{MH}$ and $\mathrm{SH}$ contributed equally to this work.

\section{References}

1 Goate AM, Chartier-Harlin MC, Mullan M et al: Segregation of a missense mutation in the amyloid precursor protein gene with familial Alzheimer's disease. Nature 1991; 349: 704-706.

2 Sherrington R, Rogaev El, Liang $\mathrm{Y}$ et al: Cloning of a gene bearing missense mutations in early-onset familial Alzheimer's disease. Nature 1995; 375: 754-760.

3 Levy-Lahad E, Wasco W, Poorkaj P et al: Candidate gene for the chromosome1 familial Alzheimer's disease locus. Science 1995; 269: 973-977.

4 Rogaev El, Sherrington R, Rogaeva EA et al: Familial Alzheimer's disease in kindreds with missense mutations in a gene on chromosome1 related to the Alzheimer's disease type 3 gene. Nature 1995; 376: 775-778.

5 Perez-Tur J, Froelich S, Prihar G et al: A mutation in Alzheimer's disease destroying a splice acceptor site in the presenilin-1 gene. NeuroReport 1995; 7: 297-301.

6 Kwok JB, Taddei K, Hallupp M et al: Two novel (M233T and R278T) presenilin-1 mutations in early-onset Alzheimer's disease pedigrees and preliminary evidence for association of presenilin-1 mutations with a novel phenotype. NeuroReport 1997; 8: 1537-1542.

7 Sato S, Kamino K, Miki T et al: Splicing mutation of presenilin-1 gene for early-onset familial Alzheimer's disease. Hum Mutat 1998; 1: Suppl. 91-94.

8 Crook R, Verkkoniemi A, Perez-Tur J et al: A variant of Alzheimer's disease with spastic paraparesis and unusual plaques due to deletion of exon 9 of presenilin 1. Nat Med 1998; 4: 452-455.

9 Tysoe C, Whittaker J, Xuereb J et al: A presenilin-1 truncating mutation is present in two cases with autopsy-confirmed earlyonset Alzheimer's disease. Am J Hum Genet 1998; 62: 70-76.

10 De Jonghe C, Cruts M, Rogaeva EA et al: Aberrant splicing in the presenilin-1 intron 4 mutation causes presenile Alzheimer's disease by increased A $\beta 42$ secretion. Hum Mol Genet 1999; 8: 1529-1540.

11 Steiner H, Romig $\mathrm{H}$, Crim MG et al: The biological and pathological function of the presenilin-1 Deltaexon 9 mutation is independent of its defect to undergo proteolytic processing. J Biol Chem 1999; 274: 7615-7618.
12 McKhann G, Drachman D, Folstein M, Katzman R, Price D, Stadlan EM: Clinical diagnosis of Alzheimer's disease: report of the NINCDS-ADRDA Work Group under the auspices of Department of Health and Human Services Task Force on Alzheimer's Disease. Neurology 1984; 34: 939-944.

13 Vandenplas S, Grobler-Rabie A, Brebner K et al: Blot hybridization of genomic DNA. J Med Genet 1984; 21: 164-172.

14 Isola J, Devries S, Chu L, Ghazvin S, Waldman F: Analysis of changes in DNA sequence copy number by comparative genomic hybridization in archival paraffin-embedded tumor samples. Am J Pathol 1994; 145: 1301-1308.

15 Hutton $M$, Busfield F, Wragg $M$ et al: Complete analysis of the presenilin 1 gene in early onset Alzheimer's disease. NeuroReport 1996; 7: 801-805.

16 Sheffield VC, Weber JL, Buetow KH et al: A collection of tri- and tetranucleotide repeat markers used to generate high quality, high resolution human genome-wide linkage maps. Hum Mol Genet 1995; 4: 1837-1844.

17 Wragg $M$, Hutton $M$, Talbot $C$, the Alzheimer's disease collaborative group: Genetic association between intronic polymorphism in presenilin-1 gene and late-onset Alzheimer's disease. Lancet 1996; 347: 509-512.

18 Dermaut B, Cruts M, Slooter AJC et al: The Glu318Gly substitution in presenilin 1 is not causally related to Alzheimer's disease. Am J Hum Genet 1999; 64: 290-292.

19 Rogaev El, Sherrington R, Wu C et al: Analysis of the 5' sequence, genomic structure, and alternative splicing of the presenilin-1 gene (PSEN1) associated with early onset Alzheimer's disease. Genomics 1997; 40: 415-424.

20 Mirra SS, Heyman A, McKeel D et al: The Consortium to establish a registry for Alzheimer's disease (CERAD). Part II. Standardization of the neuropathologic assessment of Alzheimer's disease. Neurology 1991; 41: 479-486.

21 Nyström-Lahti M, Kristo P, Nicolaides NC et al: Founding mutations and Alu-mediated recombination in hereditary colon cancer. Nat Med 1995; 1: 1203-1206.

22 Puget N, Sinilnikova OM, Stoppa-Lyonnet D et al: An Alumediated 6-kb duplication in the BRCAl gene: a new founder mutation. Am J Hum Genet 1999; 64: 300-302.

23 Rüdiger NS, Gregersen N, Kielland-Brandt MC: One short wellconserved region of Alu-sequence is involved in human gene rearrangements and has homology with prokaryotic chi. Nucleic Acids Res 1995; 23: 256-260.

24 Henthorn PS, Mager DL, Huisman THJ, Smithies O: A gene del etion ending within a complex array of repeated sequence 3 ' to the human beta-globin gene cluster. Proc Natl Acad Sci USA 1986; 83: $5194-5198$.

25 Myerowitz R, Hogikyan ND: A deletion involving Alu sequences in the beta-hexosaminidase alpha-chain gene of French Canadians with Tay-Sachs disease. I Biol Chem 1987; 262: 15396-15399.

26 Borchelt DR, Thinakaran G, Eckman CB et al: Familial Alzheimer's disease-linked presenilin 1 variant elevate $A \beta 1-42 / 1-40$ ration in vitro and in vivo. Neuron 1996; 17: 1005-1013.

27 Mehta ND, Refolo LM, Eckman C et al: Increased A 442 (43) from cell lines expressing presenilin 1 mutations. Ann Neurol 1998; 43: 256-258.

28 Citron M, Westaway D, Xia W et al: Mutant presenilins of Alzheimer's disease increase production of 42-residue amyloid beta-protein in both transfected cells and transgenic mice. Nat Med 1997; 3: 67-72.

29 Sandbrink R, Zhang D, Schaeffer Set al: Missense mutations of the PS-1/S182 gene in German early-onset Alzheimer's disease patients. Ann Neurol 1996; 40: 265-266.

30 Ishii K, Ii K, Hasegawa T, Shoji S, Doi A, Mori H: Increased A $\beta$ 42(43)-plaque deposition in early-onset familial Alzheimer's disease brains with the deletion of exon 9 and the missense point mutation (H163R) in the PS-1 gene. Neurosci Lett 1997; 228: 17-20. 